\title{
Paracoccidioidomicose e tuberculose: diagnóstico diferencial
}

\section{Paracoccidioidomycosis and tuberculosis: differential diagnosis}

Thâmara Aline Bertoni'; Elisa Keiko Hirayama Takao²; José Ricardo Colleti Dias³; Terezinha Inez Estivalet Svidzinski ${ }^{4}$

unitermos

Paracoccidioidomicose

Tuberculose

Diagnóstico diferencial

\section{resumo}

É relatado o caso de um paciente portador de paracoccidioidomicose (PCM), supostamente há 15 anos, que, apesar de a baciloscopia sempre ser negativa, foi tratado empiricamente para tuberculose, por duas vezes sem melhora clínica. O diagnóstico de PCM após longo tempo, por meio de metodologia simples, chama atenção para a importância da investigação paralela de tuberculose e paracoccidioidomicose como diagnóstico diferencial em respiradores sintomáticos crônicos.

\section{abstract}

This study reports the case of a patient who allegedly had paracoccidioidomycosis (PCM) for fifteen years. Despite the fact that his baciloscopy result had always been negative, he was empirically treated for tuberculosis twice without clinical improvement. PCM diagnosis through simple methodology draws attention to the importance of parallel investigation into tuberculosis and paracoccidioidomycosis as differential diagnosis in chronic symptomatic patients. key words

Paracoccidioidomycosis

Tuberculosis

Differencial diagnosis

1. Mestra em Biociências Aplicadas à Farmácia; bioquímica do Hospital Paraná de Maringá; bolsista da Coordenação de Aperfeiçoamento de Pessoal de Nível Superior (CAPES).

2. Especialista em Análises Clínicas; bioquímica do Laboratório de Ensino e Pesquisa em Análises Clínicas do setor de Bacteriologia Clínica da Universidade Estadual de Maringá (UEM).

3. Especialista em Clínica Médica; infectologista da Secretaria de Saúde de Maringá.

4. Doutora-coordenadora do curso de mestrado em Biociências Aplicadas à Farmácia; pesquisadora pelo Conselho Nacional de Desenvolvimento Científico e Tecnológico (CNPq).

Este trabalho é parte de dissertação de mestrado do Programa de Pós-Graduação em Biociências Aplicadas à Farmácia/UEM.

Agência financiadora: este projeto recebeu auxilio financeiro da Fundação Araucária. 
A paracoccidioidomicose (PCM) é uma micose sistêmica grave, importante problema de saúde pública, apresentase sob duas principais formas clínicas: aguda ou subaguda (juvenil) e crônica (adulto). A faixa etária mais acometida é entre 30 e 50 anos, fase mais produtiva da vida, e mais de $90 \%$ dos casos são do sexo masculino ${ }^{(17)}$.

A mortalidade por PCM é alta, e os estudos apontam a doença como a oitava causa de óbito entre as doenças infecciosas e parasitárias predominantemente crônicas no Brasil(17); no Paraná é classificada em quinto lugar nesse grupo de doenças. $O$ índice de mortalidade é considerável, foram documentadas taxas de 3,48 mortes/milhão de habitantes ${ }^{(2)}$.

Na clínica, o diagnóstico de PCM é considerado simples, porém o grande número de outras afecções com as quais pode ser confundida acaba dificultando um pouco. A forma crônica exige diagnóstico diferencial com doenças que envolvem as mucosas como câncer, leishmaniose cutâneo-mucosa, sífilis secundária ou terciária, sarcoidose, histoplasmose ${ }^{(2,12,13)}$. No entanto, grande atenção deve ser dada à tuberculose (TB) devido à sobreposição das histórias clínica e epidemiológica. Além disso, as duas doenças podem coexistir numa frequência aproximada de 5,5\% a $14,4 \%$ dos $\operatorname{casos}^{(14,16)}$. A problemática maior é a própria indicação do tratamento empírico anti-TB, uma vez que a sensibilidade da baciloscopia para TB é baixa (varia de $50 \%$ a $80 \%)^{(5)}$.

Neste relato, o diagnóstico de PCM ocorreu tardiamente, por meio de técnicas simples de visualização do fungo em escarro, após aproximadamente 15 anos de queixa respiratória e investigação, diagnósticos e tratamentos exclusivos para TB.

\section{Relato de caso}

Homem de 74 anos, portador de diabetes mellitus (DM) insulinodependente em tratamento, com diagnóstico de doença pulmonar obstrutiva crônica (DPOC) e quadro de depressão. História de tabagismo e etilismo por cerca de 30 anos. Residiu na região de Mirandópolis, interior do estado de São Paulo, até aproximadamente 20 anos de idade. Como ocupação principal, na maior parte de sua vida foi motorista de caminhão, transportando agrotóxicos. Há 15 anos queixava-se de dor torácica e tosse produtiva crônica, além de dispneia progressiva aos pequenos e médios esforços. Na época, foram realizadas inúmeras baciloscopias de escarro, todas negativas, entretanto vários exames radiológicos de tórax mostravam infiltrado pulmonar, com derrame pleural à esquerda em algumas situações.

Recebeu tratamento empírico para TB por duas ocasiões: há 15 anos, no início da história, e recentemente, uma vez que as imagens aos raios $X(R X)$ de tórax se mantinham com infiltração em ápice bilateral. Nessa ocasião, a pesquisa de bacilo álcool-ácido-resistente (BAAR) manteve-se negativa, apesar de uma reação de purified protein derivative (PPD) forte, igual a $10 \mathrm{~mm}$.

Esse tratamento não resultou em melhora, ao contrário, houve piora do estado geral do paciente, emagrecimento e permanência das imagens pulmonares, mesmo com tratamento para TB. Somente nessa fase, amostras de escarro e sangue do paciente foram incluídas em um projeto do laboratório de micologia para a pesquisa de PCM.

Cinco amostras de escarro foram analisadas, das quais duas exibiram estruturas fúngicas compatíveis com Paracoccidioides brasiliensis (Figura 1). Esses achados foram confirmados pela técnica de impregnação pela metenamina-prata, segundo Gomori-Grocott, em esfregaços de escarro (Figura 2). $\mathrm{O}$ teste de imunodifusão radial dupla ${ }^{(4)}$, exame sorológico de rotina, apresentou resultado negativo, porém teste de maior sensibilidade, o western blot, mostrou anticorpos contra o componente marcador da PCM (Figura 3). Além disso, a reação de ensaio imunossorvente ligado à enzima (ELISA) ${ }^{(10)}$ também indicou para a presença de níveis elevados de anticorpos frente ao antígeno de $P$. brasiliensis

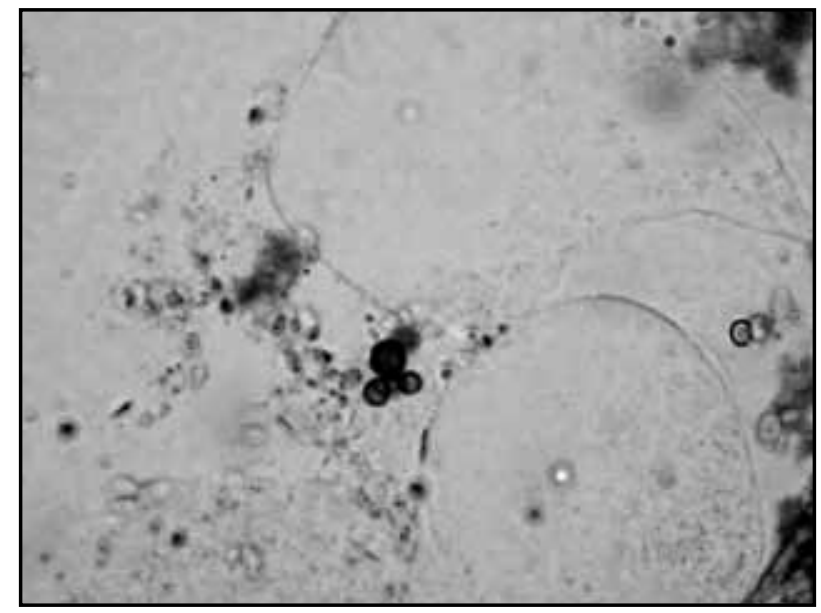

Figura 1 - Exame micológico direto de amostras de escarro fluidificadas com ditioeritritol (Sigma ${ }^{\otimes}$ D-8161) e preparadas a fresco com tinta QuinK $+\mathrm{KOH} 20 \%$, evidenciando estruturas compativeis com P. brasiliensis em aumento de 400x 


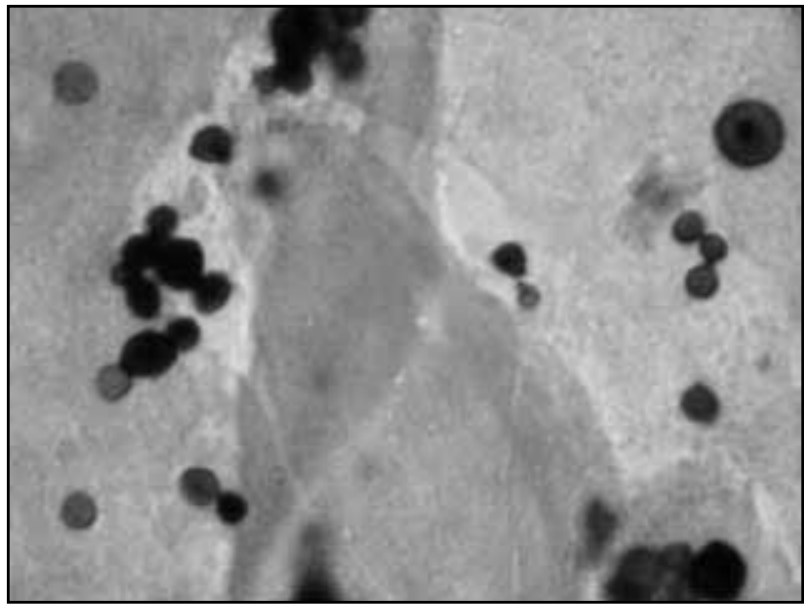

Figura 2 - P. brasiliensis em esfregaço de escarro corado pela técnica de GomoriGrocott em aumento de $400 x$

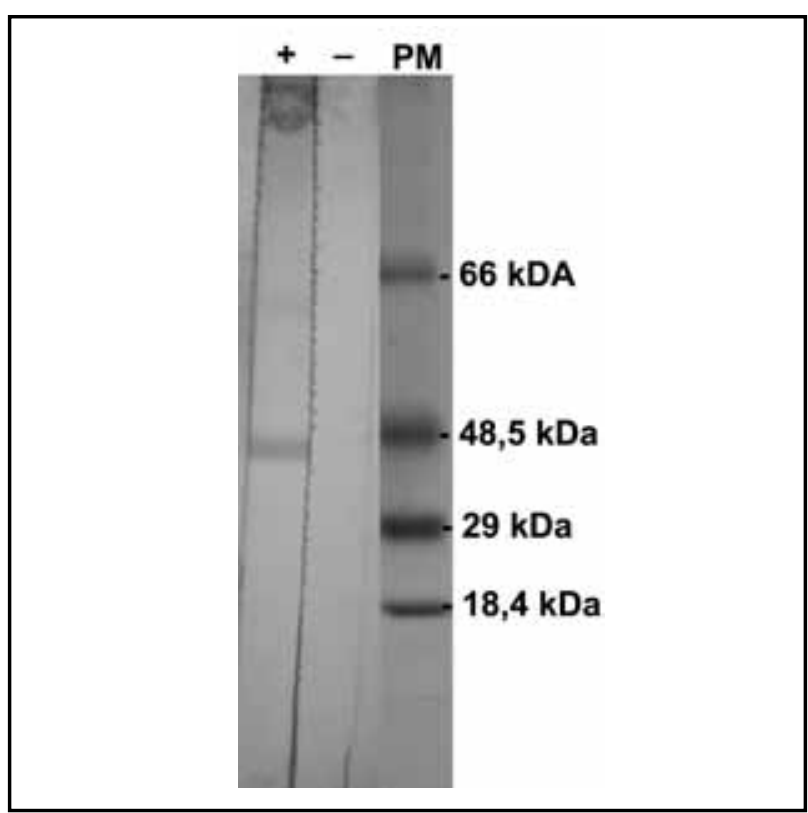

Figura 3 - Resultados da sorologia por western blot, realizada para confirmação do caso: linha (+): soro do paciente revelando a presença de anticorpos produzidos contra o componente de 43KDa; linha (-): soro controle negativo; linha (PM): padrão de pesos moleculares

\section{Discussão}

A combinação de PCM e TB é reconhecida de longa data ${ }^{(15)}$, podendo ocorrer de forma simultânea ou sequencial. O diagnóstico é simples em pacientes atendidos por profissionais experientes, em grandes centros, mas pode ser complicado nas fases iniciais da enfermidade, período em que os sinais clínicos e radiológicos nem sempre permitem clara distinção entre as doenças ${ }^{(14)}$. Infelizmente, em muitas regiões distantes do país, a carência de recursos humanos qualificados dificulta ainda mais o diagnóstico clínico da
TB; além disso, muitas vezes os laboratórios são pouco preparados para a confirmação laboratorial, tornando difícil o diagnóstico diferencial entre PCM e TB.

A PCM tem como agente o fungo termodimórfico $P$. brasiliensis, que infecta o homem por meio da inalação de conídios, estruturas de reprodução do fungo produzidas na fase filamentosa $\left(25^{\circ} \mathrm{C}\right)$ presente em solos úmidos de regiões com temperaturas amenas (em torno de $\left.20^{\circ} \mathrm{C}\right)^{(7)}$. É uma micose de grande interesse e prevalência nos países da América Latina, evolui frequentemente para o óbito se não diagnosticada e tratada de forma específica ${ }^{(17)}$.

Apesar de a infecção primária ocorrer por via inalatória, o fungo costuma atingir vários órgãos e sistemas, por disseminação hematogênica, originando ampla gama de manifestações clínicas, mas sem evidências de transmissão homem-homem ${ }^{(1)}$.

Testes sorológicos contribuem para o diagnóstico de $\mathrm{PCM}^{(19)}$, mas a confirmação é dada pela demonstração direta das células multibrotantes características em amostras biológicas, ou o isolamento do fungo desses espécimes. Acredita-se que os casos de PCM sejam subestimados no Brasil, especialmente no interior do país, o que se justifica por várias razões: variabilidade de manifestações clínicas, semelhança com outras doenças e menor valorização das micoses, que acabam negligenciando a PCM em relação à TB. Em regiões distantes dos grandes centros, a PCM ainda não é incluída entre as hipóteses diagnósticas de sintomáticos respiratórios. Contudo, testes de intradermorreação indicam que mais de $40 \%$ da população que vive em áreas endêmicas teve contato com o fungo ${ }^{(6)}$, indicativo epidemiológico importante que justifica a investigação da PCM em todos os respiradores sintomáticos residentes nessas regiões.

Além do contato com o fungo e da falha nos mecanismos de defesa do hospedeiro, alguns hábitos de vida contribuem para o desenvolvimento da PCM, como etilismo crônico, desnutrição e tabagismo, todos relatados pelo paciente sujeito deste relato. Essas condições são comuns em trabalhadores rurais de baixo nível socioeconômico e representam riscos importantes na progressão da doença, pois interferem na formação do granuloma e no mecanismo de defesa do hospedeiro. O paciente aqui investigado assumiu o hábito de ter consumido bebida alcoólica diariamente por mais de trinta anos, o que, segundo Martinez e Moya ${ }^{(11)}$, teria grande importância na patogenia da forma crônica da PCM. Além disso, o DM é considerado um fator predisponente para infecções fúngicas devido ao imunocomprometimento atribuído à diminuição da 
capacidade defensiva dos neutrófilos polimorfonucleares e dos linfócitos T e também pela angiopatia e neuropatia diabéticas ${ }^{(18)}$.

É evidente que a TB continua sendo causa de grande preocupação, a Organização Mundial da Saúde (OMS) estima que um terço da população mundial esteja infectada com Mycobacterium tuberculosis. Dessas pessoas, oito milhões anualmente desenvolvem TB ativa e dois milhões morrem por essa enfermidade a cada ano( ${ }^{(9)}$. História clínica e imagens radiológicas permitem fundamentar suspeita de $T B$, mas que deve ser confirmada. $O$ achado de BAAR em espécimes como escarro ou lavado brônquico é o método confirmatório da TB pulmonar. No entanto, a sensibilidade desse método é reconhecidamente baixa, variando entre $50 \%$ e $80 \%{ }^{(5)}$. Considerando que aproximadamente metade dos pacientes com TB pode apresentar baciloscopia de escarro negativa, é indicado o início do tratamento com tuberculostáticos, visando beneficiar o paciente e contribuir para o controle da TB na comunidade ${ }^{(9)}$. Contudo, essa recomendação é justamente um dos fatores responsáveis pelo tratamento equivocado de pacientes com PCM como se fossem TB positivos abacilíferos. $O$ indicado seria, antes da medicação, realizar exames mais sensíveis, como broncoscopia, tomografia de tórax e, sobretudo, cultura de amostras pulmonares, incluindo biópsia transbrônquica, líquido pleural, entre outros para confirmação da TB.

Os preditores para a TB pulmonar, quando a baciloscopia resulta negativa, incluem: teste da tuberculina, linfadenopatia cervical ou mediastinal, lesões cavitárias nos pulmões, história de contato com TB, tosse por mais de três semanas e perda de peso ${ }^{(5)}$. No entanto, esses sinais não podem ser atribuídos indubitavelmente à TB. De acordo com Lee et al.(9), um RX de tórax inicial com "áreas de neblina" consolidadas poderia ser um sinal independente para implementação de tratamento empírico anti-TB. No entanto, alterações radiológicas causadas na PCM e TB não são específicas nem fecham diagnóstico para qualquer das doenças. Imagens radiológicas alteradas em tórax são frequentes no exame de rotina de pacientes com doenças pulmonares. Porém, as imagens encontradas podem ser semelhantes em vários tipos de agressão inflamatória imposta ao parênquima pulmonar ${ }^{(8)}$.

Neste relato, o tratamento empírico para TB foi realizado por duas vezes não consecutivas, ambas sem confirmação laboratorial e sem melhora clínica do doente. Os pacientes que não têm diagnóstico bacteriológico de TB (baciloscopia e cultura negativas), segundo o Ministério da Saúde (MS) devem ser encaminhados para locais de referência, com mais condições de fazer o diagnóstico diferencial. Destacamos, entretanto, que, nesse caso, embora o paciente sempre tenha sido assistido em laboratório de referência tanto para TB quanto para PCM, que é o Laboratório de Ensino e Pesquisa em Análises Clínicas (LEPAC) da Universidade Estadual de Maringá (UEM), nunca houve um pedido médico para a investigação de outras doenças que não a TB.

Na verdade, não é possível afirmar com precisão se o paciente teve PCM unicamente ou se sofria das duas doenças, porém o fato é que o diagnóstico de PCM somente ocorreu depois de muito tempo de queixas pulmonares graças à implantação de um projeto de pesquisa, que investiga PCM em todas as amostras de escarro encaminhadas para pesquisa de BAAR. Embora não houvesse suspeita de PCM, tão logo houve a confirmação laboratorial, iniciou tratamento com itraconazol $200 \mathrm{mg} / \mathrm{dia}$, segundo preconiza a Secretaria de Saúde do Estado do Paraná(17), e encontra-se em acompanhamento com infectologista, já evidenciando sinais de melhora.

Entre os testes sorológicos para PCM, a imunodifusão radial dupla é o único validado, é simples, de baixo custo e de grande importância, principalmente para a monitoração do tratamento da doença. Seu ponto limitante é a baixa sensibilidade, um resultado negativo, como ocorreu nesse caso, não exclui a possibilidade de $\mathrm{PCM}^{(3)}$, além de inviabilizar o acompanhamento do tratamento. Testes mais sensíveis, como ELISA e western blot, prometem incrementar a sensibilidade e a especificidade dos métodos imunológicos para diagnóstico e acompanhamento da PCM. Nesse caso, a evidenciação de anticorpos produzidos contra o componente de $43 \mathrm{kDa}$, considerado específico para $P$. brasiliensis, está de acordo com o achado inquestionável do fungo no escarro no exame micológico direto. Esse exame é simples, extremamente barato e pode ser implantado em laboratórios clínicos de qualquer porte.

A decisão de submeter o relato desse paciente visa chamar a atenção dos profissionais da saúde para a importância da investigação paralela de TB e PCM. Somente dessa forma será possível confirmar a comorbidade e afastar o risco de doentes de PCM serem tratados para TB, mesmo sem o achado microbiológico de BAAR, preocupação registrada desde $1968^{(15)}$. Não é mais permitido considerar apenas teoricamente o fato de as duas doenças se sobreporem clínica e epidemiologicamente. Informações clássicas da literatura e da academia precisam ser refletidas na prática pela investigação das duas doenças concomitantemente. 


\section{Referências}

1. ALMEIDA, O. P., JACKS, J.Jr. Paracoccidioidomycosis of the mouth: an emerging deep mycosis. Crit Rev Oral Biol Med, v. 14, p. 377-83, 2003.

2. BITTENCOURT, J. I. M. et al. Paracoccidioidomycosis mortality in the State of Paraná, Brazil, 1980/1998. Cad Saúde Publica, v. 21, n. 6, p. 1856-64, 2005.

3. BLOTTA, M. H. S. L. et al. Endemic regions of Paracoccidioidomycosis in Brazil: a clinical and epidemiologic study of 584 cases in the southeast region. Am J Trop Med Hyg, v. 61, n. 3, p. 390-4, 1999.

4. CAMARGO, Z. P. et al. Production of Paracoccidioides brasiliensis exoantigens for Immunodiffusion tests. J Clin Microbiol, v. 26, p. 2147-51, 1998.

5. CASTELO FILHO, A. et al. II Congresso brasileiro de tuberculose: diretrizes brasileiras para tuberculose 2004. J Bras Pneumol, v. 30, Supl 1, 2004.

6. FORNAJEIRO, N. et al. Inquérito epidemiológico sobre a paracoccidioidomicose utilizando a gp43 em dois municípios do noroeste do Paraná, Brasil. Rev Soc Bras Med Trop, v. 38, n. 2. p. 191-3, 2005.

7. FRANCO, M. et al. A critical analysis of isolation of Paracoccidioides brasiliensis from soil. Med Mycol, v. 38, p. 185-91, 2000.

8. GOMES, E. et al. Dissociação clínico-radiológica nas manifestações pulmonares da paracoccidioidomicose. Rev Soc Bras Med Trop, v. 41, n. 5, p. 454-8, 2008.

9. LEE, W. J. et al. Response to empirical anti-tuberculosis treatment in patients with sputum smear-negative presumptive pulmonary tuberculosis. Respiration, v. 72, p. 369-74, 2005.

10. MALUF, M. L. F. etal. Prevalência de paracoccidioidomicose: infecção determinada através de teste sorológico em doadores de sangue na região Noroeste do Paraná,
Brasil. Rev Soc Bras Med Trop, v. 36, n. 1, p. 11-6, 2003.

11. MARTINEZ, R., MOYA, M. J. Associação entre paracoccidioidomicose e alcoolismo. Rev Saúde Pública, v. 26, n. 1, p. 12-6, 1992.

12. NEGRONI, B. R. et al. Paracoccidioidomicosis. In: TORRES RODRIGUEZ. J. M. Introducción a la micología médica. México: Ed Panamericana, 1995. p. 263-73.

13. PATO, A. M. et al. Paracoccidioidomicosis asociada a otras patologías respiratorias en un hospital de Corrientes, Argentina. Rev Arg Microbiol, v. 39, n. 3, p. 161-5, 2007.

14. QUAGLIATO, R. J. et al. Association between paracoccidioidomycosis and tuberculosis: reality and misdiagnosis. J Bras Pneumol, v. 33, n. 3, p. 295300, 2007.

15. REGO, A. P. et al. Falhas no diagnóstico de internação em hospitais de tuberculose: a blastomicose sul-americana como causa de erro. Rev Med Est Guanabara, v. 35, p. 104-12, 1968.

16. SANTO, A. H. et al. Tendência da mortalidade relacionada à paracoccidioidomicose, Estado de São Paulo, Brasil, 1985 a 2005: estudo usando causas múltiplas de morte. Rev Panam Salud Publica, v. 23, n. 5, p. 31324, 2008.

17. SHIKANAI-YASUDA, M. A. et al. Consenso em paracoccidioidomicose. Rev Soc Bras Med Trop, v. 39, n. 3, p. 297-310, 2006.

18. SHIP, J. A. Diabetes and oral health: an overview. J Am Dent Assoc, v. 134 (Spec №), p. 4S-10S, 2003.

19. VALLE, A. C. F. et al. Interpretation and clinical correlation of serological tests in paracoccidioidomycosis. Med Mycol, v. 39, p. 373-7, 2001. 